\title{
TOTALITARISMO, GNOSTICISMO E PNEUMOPATOLOGIA: UM ESTUDO A PARTIR DA FILOSOFIA DE ERIC VOEGELIN*
}

\author{
[TOTALITARISM, GNOSTICISM AND PNEUMOPATHOLOGY: A STUDY FROM THE ERIC \\ VOEGELIN'S PHILOSOPHY]
}

\author{
Rodolfo Rodrigues Medeiros ** \\ Instituto Federal de Educação, Ciência e Tecnologia do R. G. do Norte, Brasil \\ Galileu Galilei Medeiros de Souza *** \\ Universidade Estadual do Rio Grande do Norte, Brasil
}

Resumo: Esse artigo contém discussões a respeito da análise promovia pelo filósofo alemão Eric Voegelin (1901-1985) acerca dos fatores que contribuíram para a insurreição dos movimentos totalitários. Na ótica voegeliniana, o fundamento do surgimento e adesão a esses movimentos deve ser procurado não só nas formas e instituições político-jurídicas, mas em aspectos associados a fatores espirituais, como o secularismo moderno e o "estado de espírito" dos cidadãos atraídos pelos totalitarismos. A problemática que permeia este trabalho gira em torno da seguinte questão: que condições favoreceram o advento dos movimentos totalitários? A hipótese desenvolvida baseia-se na ideia de que os valores, concepções e ideais gnósticos influenciaram os fundamentos ideológicos dos regimes totalitários e contribuíram para a "decadência ou desordem espiritual" dos indivíduos envolvidos pelos referidos movimentos. Essa desordem espiritual é uma espécie de enfermidade intelectual e ética que Voegelin denomina de pneumopatologia, uma doença do espírito. As reflexões e discussões que fundamentam esta empresa serão promovidas por meio de revisão bibliográfica, tendo como referências principais as obras A Nova Ciência da Política e Hitler e os Alemães. O intento deste artigo é compreender os fatores espirituais que acabaram contribuindo para a ascensão dos regimes totalitários, centrando a análise no fenômeno da peneumopatologia como um dos elementos condicionantes da adesão aos
ABSTRACT: This article contains discussions about the analysis promoted by the German philosopher Eric Voegelin (1901-1985) about the factors that contributed to the insurrection of the totalitarian movements. From the Voegelinian point of view, the basis for the emergence and adherence to these movements must be sought not only in political-juridical forms and institutions, but in aspects associated with spiritual factors, such as modern secularism and the "state of mind" of citizens attracted by totalitarianisms. The problematic that permeates this work revolves around the following question: what conditions favored the advent of totalitarian movements? The hypothesis developed is based on the idea that Gnostic values, conceptions and ideals influenced the ideological foundations of totalitarian regimes and contributed to the "spiritual decay or disorder" of the individuals involved in these movements. This spiritual disorder is a kind of intellectual and ethical illness which Voegelin calls pneumopathology, a disease of the spirit. The reflections and discussions that underlie this company will be promoted through literature review, having as main references the works The New Science of Politics and Hitler and the Germans. The purpose of this paper is to understand the spiritual factors that eventually contributed to the rise of totalitarian regimes, focusing the analysis on the phenomenon of peneumopathology as one of the conditioning elements of adherence to the movements

** Professor de Filosofia do Instituto Federal de Educação, Ciência e Tecnologia do Rio Grande do Norte-IFRN, Campus Caicó.E-mail: rodolfo.caico@hotmail.com.***Professor Adjunto IV e Coordenador do Curso de Licenciatura em Filosofia da Universidade Estadual do Rio Grande do Norte-UERN/Campus Caicó. E-mail: galileumed@yahoo.com.br 
movimentos citados, por ceder às condições que favoreceram a manipulação ideológica totalitária. O trabalho será assim disposto: a discussão inicial apresentará as reflexões referentes ao gnosticismo, almejando evidenciar a influência de símbolos, concepções e ideias das religiões de credo imanentista na insurgência dos movimentos totalitários; no ponto posterior dar-se-á a exposição das discussões dedicadas às características da "enfermidade espiritual" que afetou os indivíduos seduzidos pelos movimentos totalitários.

Palavras-chave:

Pneumopatologia; Totalitarismo mentioned, by giving way to conditions that favored totalitarian ideological manipulation. The paper will be arranged as follows: the initial discussion will present the reflections concerning Gnosticism, aiming to highlight the influence of symbols, conceptions and ideas of the religions of immanentist creed on the insurgency of totalitarian movements; In the following section, there will be an exposition of the discussions dedicated to the characteristics of the "spiritual illness" that affected the individuals seduced by the totalitarian movements.

Gnosticismo; KEYWORDS: Gnosticism; Pneumopathology; Totalitarianisms

\section{INTRODUÇÃO}

S regimes totalitários deixaram marcas profundas na história e na política do século XX. O terror promovido por movimentos como o Nacional Socialismo alemão, o Comunismo Stalinista russo e Maoísta chinês, ou o Fascismo italiano, hoje ainda causam perplexidade. É difícil compreender como grande parcela da população dessas nações não só aceitaram o papel de colaboradores fiéis dessas ideologias e movimentos, como as justificavam politicamente.

Dentre tantos outros, cientistas políticos (como o alemão Eckhard Jesse), filósofos (a alemã Hannah Arendt), historiadores (o italiano Emilio Gentile), psicólogos (o estadunidense Stanley Milgram, o polonês Andrew Lobaczewski) e sociólogos (o polonês Zygmunt Bauman) debruçaram-se sobre o fenômeno do totalitarismo, analisando os artifícios, fatores e mecanismos que concorreram para o surgimento, ascensão e controle ideológico desses movimentos, com a esperança de que o entendimento acerca dessas questões ajudasse a identificar e evitar a repetição futura de tais acontecimentos. A matéria de estudo, então, não é nova. Porém, não caduca.

Como a atmosfera ideológica totalitária é marcada pela sobreposição de fanatismo ideológico, preconceito e violência a quaisquer motivações racionais, não é despropositado afirmar que o clima de intolerância e polarizações parece voltar a rondar as relações e disputas políticas atuais, sobremodo se levarmos em consideração a aceleração do terrorismo mundial. Nessas relações conflituosas, a religião volta novamente ao centro dos debates, ligados, ainda uma vez, ao problema da imigração. Em âmbito nacional (brasileiro), a observação das últimas eleições presidenciais (realizadas em outubro de 2018), por exemplo, deixaram evidente o ambiente de acirramento ideológico entre os adeptos de espectros políticos de esquerda e de direita, envolvendo, mais uma vez, questões religiosas de grande incidência sobre os costumes. Em todo caso, os sintomas gerais são os do choque cultural entre ideologias conflitantes, com acentuadas raízes espirituais, como ficará mais claro adiante.

Ainda que não se tenha chegado aos extremos do entreguerras, os elementos presentes no cenário mundial reascendem o interesse pelas causas da ascensão das ideologias totalitárias e do domínio ideológico que esses movimentos exerceram sobre seus seguidores. Nessa direção, a intenção do presente escrito é contribuir para uma reflexão acerca do totalitarismo, revisitando os estudos realizados pelo filósofo alemão 
Eric Voegelin (1901-1985). A escolha por Voegelin não é despropositada, dado a centralidade que essa temática ocupa em sua produção filosófica e, é claro, sua relevância. Há questões fundamentais que guiam toda a vida intelectual de um autor; no caso de Voegelin, ei-la. As reflexões voegelianas sobre o totalitarismo partem da premissa de que o fundamento do surgimento desses regimes e a adesão em massa a eles devem ser procurados não só no fracasso de formas e instituições político-jurídicas tradicionais, como também em outros aspectos do que poderíamos chamar mundo vivido (Lebenswelt), relacionados com fatores espirituais, ou seja, metafísicos, religiosos, filosóficos ou, como sugere a terminologia voegeliana, noéticos e pneumáticos.

A questão a que o presente texto se reporta diz respeito, assim, à identificação dos fatores espirituais que contribuíram para o advento dos movimentos totalitários. A hipótese desenvolvida por Voegelin se alicerça na concepção de que os valores, visões, ideias e ideais gnósticos constituem a base ideológica dos regimes totalitários, por concorrerem para a "decadência espiritual" dos sujeitos atraídos e envolvidos por eles. Essa desordem espiritual consiste em uma espécie de enfermidade intelectual e ética que Voegelin denomina de pneumopatologia, isto é, uma "doença do espírito" expressão que remonta, pelo menos, a Schelling. Para a aproximação dessa hipótese, empreenderemos uma revisão bibliográfica, que segue o procedimento da leitura analítica de textos filosóficos (ADLER; DOREN, 2010), tendo como referências essenciais as obras A Nova Ciência da Política (VOEGELIN, 1987) e Hitler e os Alemães (VOEGELIN, 2007a).

A estrutura desse artigo se distribui em duas partes. No passo inicial, será considerada a questão da influência dos ideais e elementos gnósticos em certos símbolos presentes nas ideologias totalitárias, visando evidenciar a incidência das ideias e concepções das religiões de credo imanentista na insurgência dos movimentos totalitários; o momento seguinte será destinado às discussões concernentes às causas, características e consequências da pneumopatologia.

\section{O GNOSTICISMO E OS FUNDAMENTOS IDEOLÓGICOS DOS MOVIMENTOS TOTALITÁRIOS}

Eric Voegelin não só percebe a existência de certas semelhanças entre simbolismos políticos e religiosos, como sustenta que os regimes totalitários se aproveitaram da simbologia religiosa para constituir suas bases ideológicas, promovendo um movimento de secularização. A atmosfera que permitiu o surgimento dos regimes totalitários foi construída “[...] numa grave crise, num processo de esgotamento cuja fonte se encontra na secularização do espírito, na separação de um espírito que se tomou somente mundano [...]" (VOEGELIN, 2002, p. 21). A insurgência dos regimes totalitários seria parte de uma imensa "decadência espiritual", corolário de premissas gnósticas ${ }^{1}$ que se tornaram familiares à cultura ocidental.

A "consciência gnóstica" ou o "espírito gnóstico" é, sobretudo, uma atitude "negativa", um modo negativo de encarar a existência. O gnóstico crê que o mundo é essencialmente mau, que a história é essencialmente má e que a existência pessoal é essencialmente trágica. Seu credo fundamental é a concepção do encaminhamento de tudo para a morte, degeneração, envelhecimento, ruína. O gnosticismo é "insatisfação pela existência", sentimento de "desordem cósmica". É ele o adversário maior da filosofia, pelo menos daquela clássica, entendida como busca da ordem, apoiada na crença de que o ser é presidido por ela. O gnosticismo, ao contrário, se sustenta sobre a 
crença de que o que há é caos, luta, morte, destruição, desordem, absurdo, e a atitude que se alimenta de ações consequentes a isso. Assim, ele não é uma simples doutrina, mas um movimento, inspirado por várias doutrinas, cujo traço definidor é a desilusão pela existência e a prática consequente de ações que procuram de alguma forma saná-la.

Quanto a essa última observação, o gnosticismo se alimenta e se reproduz em situações de instabilidade e de profundas mudanças sociais e políticas, que, naturalmente, abrem espaço para elaboração de novas maneiras de entender a realidade e atuar sobre ela. Na obra Ciência, Política e Gnósis ${ }^{2}$, Voegelin escreve:

A queda dos antigos impérios no Oriente, a perda da independência de Israel e das cidades-estado helênicas e fenícias, os deslocamentos da população, as deportações e a escravização, e a interpenetração das culturas colocam os homens, em cujas cabeças a história é decidida, em um estado extremo de perda diante da agitação do mundo, de desorientação espiritual, de insegurança material e anímica. A perda de um sentido de existência devido ao colapso de instituições, culturas e laços políticos deu origem à tentativa de compreender de uma nova maneira o sentido da vida humana, redescobrir o sentido da existência nas condições desse mundo. A essas tentativas pertencem, com uma ampla gama de variações em relação à profundidade de compreensão e conteúdo da verdade: a reinterpretação estoica do homem (para a qual a polis perdeu seu significado) como polite [cidadão] do kosmos, [...] as religiões dos mistérios, os cultos héliopolíticos dos escravos, a apocalíptica judaica, o cristianismo e o maniqueísmo. Nesta série aparece, como uma das mais magníficas entre as novas criações de sentido, a gnose ${ }^{3}$ (VOEGELIN, 2009b, p. 75-76).

Por "gnose" se denominam muitas doutrinas, mais ou menos esparsas, que possuem como característica comum o esforço organizado por atingir uma redenção para o homem a partir do próprio homem, mais especificamente por uma via de conhecimento, capaz de explicar a realidade, suas crises, seus desencantos e tragédias. Por essa ótica, o gnosticismo aparece como uma luta, um ato de resistência e revolta contra um mundo desprovido de sentido. O ser humano, envolto nesse redemoinho de mudanças sociais, culturais, políticas e religiosas, que acabam afetando o seu pensamento, seus costumes, suas crenças, sua vida, é impulsionado a defender-se contra a tragicidade do mundo, procurando mudá-la por sua ação. Em síntese, “[...] a insatisfação com o mundo, como tal, que leva ao desejo de transformar o mundo através da ação política, é o que engendra o gnosticismo" (FEDERECI, 2011, p. 89-90).

Isso se aplica quer ao gnosticismo antigo, quer ao moderno. Com algumas variações, esses são resultantes de mudanças sociais que empurraram em direção ao rompimento com a tradição, em uma postura de oposição a um mundo que "não é mais tão bem ordenado, o kosmos em que o homem helênico se sentia em casa; não é o mundo judaico-cristão que Deus criou e achou bom" " (VOEGELIN, 2009b, p. 76-77).

As raízes do gnosticismo moderno começariam a ser estabelecidas no período medieval, ganhando maior projeção a partir do século XII, por meio da interpretação da história promovida por Joaquim de Fiore 5 (1135-1202), o qual inova "[...] ao aplicar o símbolo da Trindade ao curso da História" (VOEGELIN, 1982, p. 87). Fiore divide a história humana em três eras: a do Pai, representada pela história do povo hebreu, retratada no Antigo Testamento, tendo como líder a figura de Abraão; a era do Filho, marcada pelo surgimento de Cristo; e a era do Espírito, no interior da qual "[...] predizia Joaquim que, por volta de 1260, apareceria o Dux e Babylone, o líder da terceira era" (VOEGELIN, 1982, p. 87). Essa terceira era marcaria o fim da história, tempo em que se "veria a perfeição final mediante um jorro de graça divina em todos os homens com a descida do Espírito Santo" (SANDOZ, 2010, p. 164). 
Vários símbolos considerados por Fiori se reproduziriam em movimentos gnósticos modernos. Dentre esses, pode-se elencar, pelo menos, quatro símbolos principais: "[...] a concepção da história como uma sequência de três eras [...]; o segundo símbolo é o referente ao líder [...]; o terceiro símbolo é o do profeta da nova era [...]; o quarto símbolo é o da irmandade de pessoas autônomas [...]" (VOEGELIN, 1982, p. 87-88).

A respeito da divisão da história em três eras, pode-se ver essa concepção se refletir, por exemplo, na teoria de Augusto Comte sobre as três fases do desenvolvimento histórico, filosófico e epistemológico do espírito humano (teológico, metafísico e positivo); no símbolo da Terceira Roma Fascista (a primeira foi a Antiga e a segunda, a Cristã); assim como na ideia do Terceiro Reich nacional-socialista alemão (o Primeiro Reich teria terminado em 1806 e o Segundo seria o Reich de Bismarck, que teve seu fim em 1918). O segundo símbolo, o do líder, tido como responsável pela mudança/revolução que garantirá a realização do destino prometido, pode ser antevisto no movimento dos religiosos franciscanos adeptos da interpretação de São Francisco como a realização da profecia do Dux e Babylone de Joaquim de Fiore; no superhomem nietzschiano; no que representaram Mussolini, Hitler e Stálin para suas nações e ideologias. O terceiro símbolo, o do profeta, reflete-se na figura do próprio Joaquim de Fiore (que anuncia o Dux e Babylone); pode ser associado a Marx (anunciador da queda do capitalismo e da luta de classes que levaria ao comunismo); a Comte (que apresenta o homem positivista como último estágio do desenvolvimento humano) ou mesmo a Nietzsche (ao prenunciar o super-homem como destino da humanidade). $\mathrm{O}$ último símbolo, por fím, o da irmandade autônoma, aparece no Comunismo Marxista, uma vez que em sua plena realização o Comunismo seria marcado pela ausência do Estado, a não necessidade de um poder centralizador, no Facismo e no NacionalSocialismo, que falam de comunidades ligadas por cultura, sangue e terra (VOEGELIN, 1982; 2002).

Segundo a interpretação de Voegelin (1982, 2002), é justamente a mudança de perspectiva que o gnosticismo opera a criar as condições para a manipulação das massas, condição sine qua non dos regimes totalitários. Que mudança foi essa e como ela contribuiu para os movimentos de massa?

A modificação promovida pelo gnosticismo baseia-se na construção de uma narrativa que procurar falar de uma escatologia intramundana. As massas, tendo perdido seus laços culturais e religiosos, que antes significavam suas existências, facilmente preenchem a lacuna remanescente com a crença em um projeto intramundano de felicidade escatológica, que revira a tradição escatológica cristã ao inverso:

no cristianismo e nas ideologias gnósticas há um movimento paralelo da queda à ascensão. O cristão, no entanto, antevê a ascensão, o movimento em direção à perfeição humana, como um movimento fora da história no Para Além, ao passo que o gnóstico concebe essa perfeição do homem como um acontecimento na história (FEDERECI, 2011, p. 90-91).

A simbologia gnóstica imanentista ganha espaço no ocidente a partir da "crise" da fé que marca o surgimento do mundo moderno. Com a diminuição da influência cultural do Cristianismo, em favor de um amplo programa de conhecimento que opõe razão e religião, e no investimento em novas metodologias científicas, o gnosticismo apresenta-se como uma alternativa que aponta para um novo sentido, intramundano, uma "fé imanente" substituindo a fé transcendental. O gnosticismo promove uma ressignificação da escatologia, segundo a qual o fim transcendente (típico do cristianismo tradicional e da filosofia clássica grega) é substituído por uma visão 
imanentista do destino humano (traço gnóstico), e é essa mudança que Voegelin denomina de "imanentização do eschaton cristão":

Prometia o que o cristianismo não prometia: assegurava o livrar-se da miséria do mundo por meio da perfeição de existência no tempo, isto é, pela transfiguração do mundo e do homem através do apocalipse do super-homem. [...] A imanentização dos simbolismos clássico e cristão por Joaquim e seus sucessores dá ensejo, no século XIX, à radical secularização de Feuerbach, Marx, Comte e Nietzsche. O fio especificamente moderno da política contemporânea é identificado com as variedades gnósticas de crença dogmática que formam um espectro de doutrinas inter-relacionadas dinamicamente, desde o progressismo e idealismo na direita até o ativismo revolucionário na esquerda. Expressão da teologia civil dominante da sociedade moderna, a forma final gnóstica é o Estado Totalitário do século XX como exemplificado na banalidade patente e brutalidade da Alemanha Nacional-Socialista e na Rússia Comunista (SANDOZ, 2010, p. 167).

Os valores cristãos transcendentes, que por muito formaram o alicerce dos costumes, pensamentos e crenças da cultura ocidental, a partir da modernidade diminuem consideravelmente o prestígio que detinham, desorientando a bússola moral, espiritual e existencial que por séculos guiou o ocidental comum. Potencialmente, o vazio resultante poderia ser preenchido por outros projetos civilizacionais. E é o que ocorre, segundo Voegelin $(1982,2002)$. O afastamento dos ideais cristãos permite que o líder ideológico conduza a massa para certa "desdivinização" da vida. Enquanto a religião é transcendente, a vida humana permanece "sagrada", porque entendida como criação de Deus. Com a imanentização, a visão de mundo resultante passa a considerar a ideologia (facismo, comunismo, nacional-socialismo), ou seja, a criação humana que promete a realização do destino imanente, como "sagrada", "divina". O irmão é o companheiro ideológico, os outros que não comungam dessa visão são "inferiores" ou "inimigos". O líder do movimento é considerado um messias, que traz a resolução próxima dos problemas presentes, construindo uma nova ordem, onde antes só havia caos.

Ora, a crença de que há uma ordem independente e transcendente, sob a qual o homem deve guiar sua existência, traduz-se como uma exigência de humildade. ${ }^{6}$ Sem essa, não há freios e contrapesos que o convençam que ele próprio - e suas ambições -, não seja o centro da existência e o criador de sua própria norma. Acrescente-se a isso um certo grau de psicopatologia ${ }^{7}$, e a fórmula estará potencializada.

Segundo Voegelin (1982, 2002, 2007a, 2007b), essa "decadência ou desordem espiritual", da qual se aproveita e com a qual contribui o gnosticismo - e, com ele, os movimentos totalitários -, se configura como uma "doença do espírito". Os traços e consequências dessa enfermidade espiritual serão esclarecidas a seguir.

\section{PNeUmopatologia: CONDiÇÃo da MANipulaÇão IDEOLÓGICA TOTALITÁRIA}

Na obra Hitler e os Alemães, Voegelin (2007a) busca compreender os fatores que possibilitaram o surgimento e ascensão do Nacional Socialismo na Alemanha. Muitos estudiosos dedicaram-se a compreender o que tornou isso possível, e grande parte das investigações a esse respeito centram-se na análise da figura de Hitler, por vezes atribuindo a ele um poder de fascínio quase sobrenatural, descrevendo-o como alguém que com sua oratória "mágica" e seu carisma irresistível foi capaz de "enfeitiçar" uma nação inteira ${ }^{8}$. Voegelin não segue esta linha de inquirição, ele não se detém na análise 
da personalidade de Hitler nem de suas "qualidades" retóricas, por compreender que não se deve "[...] isolar Hitler e analisá-lo apenas como um indivíduo excepcional. Em vez disso, pode-se ver o fenômeno de sua ascensão ao poder apenas em conexão com uma disposição do povo alemão, que levou Hitler ao poder" (VOEGELIN, 2007a, p. $83)$.

O filósofo-político, portanto, direciona sua investigação sobre o "estado de espírito" ou "disposição" dos sujeitos que são atraídos a serem apoiadores do Nacional Socialismo. Em contraste com isso, também se determinam as motivações dos que resistiram a tal movimento. Voegelin (2007a), assim, reflete acerca dos fatores que levaram o indivíduo a ser envolto pelos mecanismos e instrumentos de manipulação ideológica que promoveram a ascensão do Partido Nazista e de Hitler ao poder, sem esquecer dos que resistiram a essa maré. Com efeito, a falta de unanimidade, ainda que o apoio a Hitler e ao Nazismo tenha sido majoritário, é o indício de que essa situação não pode ser usada para demonstrar a hipótese da ausência de liberdade e completa determinação do homem por seu meio. Ora, isso considerado, a tese de uma culpa coletiva se esvazia. Voegelin (2007a) procura determinar o grau de responsabilidade seja dos indivíduos que aceitaram e seguiram o movimento totalitário, seja daqueles que a ele resistiram, ao mesmo tempo em que investiga, na origem das motivações que esses sujeitos tiveram, o contexto que ensejou a aparição do tipo de homem apto a abraçar essa causa ou a rejeitá-la. Por esse procedimento, sem negar a responsabilidade individual, estudam-se também as condições situacionais nas quais os indivíduos emergem. E a respeito dessa última perspectiva da questão, Voegelin afirma que foi "uma situação de apodrecimento intelectual e ético que, de fato, fundamentou a ascensão do fenômeno de Hitler" (VOEGELIN, 2007a, p. 80). Mas, suas conclusões não param por aí, porquanto explicita a percepção de que esse fator seria o responsável não só pela ascensão do Nacional Socialismo ao poder, mas de todos os regimes totalitários, já que ele “[...] não é apenas um problema alemão. É um problema internacional" (VOEGELIN, 2007a, p. 80).

Como já enunciado anteriormente, Voegelin (2007a) denomina essa enfermidade intelectual e ética de pneumopatologia ou "doença do espírito". Evidentemente, se há uma "doença" a ser caracterizada, essa pressupõe também o seu oposto, ou melhor, a condição do homem "espiritualmente são". Mais ainda, coloca também a questão de uma gradação entre extremos, ou seja, graus maiores e menores de doença e sanidade.

Para se aproximar desse contexto, Voegelin (2007a) aponta para lugares históricos em que essa questão tenha sido tematizada, o que aconteceu "[...] nas sociedades helênica e israelita" (VOEGELIN, 2007a, p. 117). Essas se forjam em torno do problema da constituição essencial do ser humano; ainda que cada uma aponte para uma perspectiva dessa constituição: a essência humana exaltada na experiência filosófica helênica é o nous (a razão, a inteligência); enquanto que na experiência israelita, é o pneuma (espírito). Na concepção voegeliniana, todavia, esses elementos não são excludentes nem opostos, mas concorrem mutuamente para indicar a natureza humana em sua forma mais essencial e integral: "a razão e o espírito são os dois modos de constituição do homem [...]" (VOEGELIN, 2007a, p. 117).

Quanto ao seu sentido, Nous "significa respectivamente razão, inteligência e mente. [...] Pode ser entendida, em seu aspecto mais alto, como a propriedade intuitiva da racionalidade [...]" (SANDOZ, 2010, p. 225). As análises voegelinianas do nous serão realizadas em torno da filosofia clássica, principalmente nos escritos de Platão e Aristóteles, por ele entender que "a melhor forma de retomar o contato com a realidade é recorrer a pensadores do passado que ainda não a tinham perdido ou estavam empenhados em recuperá-la" (VOEGELIN, 2007b, p. 141). A cosmologia platônica e a 
aristotélica desenvolvem-se amparadas pela concepção de que uma força superior, divina, é responsável pela ordenação de todos os seres, em uma escala de perfeição que coloca o homem no topo da existência do mundo sublunar.

As concepções cosmológicas de Platão e Aristóteles vão além daquelas elaboradas pelos filósofos que os antecederam, os chamados filósofos da physis (natureza). Esses procuravam compreender a arché (elemento originário, princípio primordial) do mundo, e até apontavam para a necessidade da ação de uma razão universal que rege a natureza (como o Logos para Heráclito, ou o Ser em Parmênides), mas com Platão e Aristóteles "a questão da arché é reformulada no sentido de que já não indaga acerca do começo do mundo, mas está preocupada com a integração do homem na ordem do ser, através da harmonia do humano com o nous divino" (VOEGELIN, 2009a, p. 216). Os filósofos da natureza procuram o fundamento do ser na natureza, mas Platão e Aristóteles encontram esse fundamento também no próprio homem; eles percebem certa equivalência entre a ordem do universo e a ordem do homem, concluindo que tal como o universo é regido por essa inteligência, a existência humana também o seria. Ademais, esse nous deve ser distinguido de outras significações que pretendem identificar a razão ou a inteligência a partir de outras tradições religiosas ou filosóficas:

[...] o nous não deve ser confundido nem com o ruach israelita de Deus, nem com o pneuma helenístico, cristão ou gnóstico, nem com a ratio do Iluminismo, nem com o Geist de Hegel. Deve ser entendido estritamente no sentido dos pensadores helênicos como o lugar onde o fundamento humano de ordem está em harmonia com o fundamento do ser (VOEGELIN, 2009a, p. 216).

De modo diverso do restante do universo, entretanto, a ordenação da existência humana passa por sua liberdade, de tal modo que a experiência noética feita pelo homem não é indiferente a suas escolhas, que também podem ir na direção da rejeição da ordem e, assim, do ser (VOEGELIN, 2009a). De acordo com esses dois filósofos clássicos - Platão e Aristóteles -, agir conforme o nous é, assim, agir em harmonia com o próprio princípio que rege o cosmos, o que implica no reconhecimento de uma ligação entre pensamento e ação, de tal forma a encarar sua influência mútua. O resultado de uma prática ordenada é a ordenação da "consciência" humana e vice-versa (VOEGELIN, 2009a).

Quanto ao termo pneuma - utilizado para traduzir o termo hebraico ruach -, também de origem grega, esse pode significar ar, respiração, vento, mas também espírito. Eugene Webb, na obra Eric Voegelin: philosopher of history ${ }^{9}$, destaca que, na acepção voegeliniana pneuma é, sobretudo, espírito: “[...] a presença do polo transcendental [sic!] da tensão da existência como uma força que ordena a alma a partir de dentro"10 (WEBB, 2014, 1. 5006. Nota do tradutor). O nous é o motor da inquirição filosófica, o pneuma, da inspiração divina. O nous é o espírito visto em um movimento que vai do indivíduo para a transcendência, quer dizer, do homem em busca do fundamento divino do Ser; o pneuma é o espírito visto na perspectiva do movimento oposto, do Ser divino em direção ao homem. Distinguíveis, mas não separáveis, nous e pneuma são perspectivas que confluem para elucidar a essência do homem:

Quando a consciência de ordem, movida pela tensão existencial em direção ao fundamento, atinge a luminosidade de experiências noéticas e pneumáticas, ela encontra o que significa, essencialmente, ser humano. Esse conhecimento da humanidade essencial [Menschenwesenlichkeit] interpreta a si mesmo através dos símbolos "homem" e "humanidade" (VOEGELIN, 2009a, p. 500-501).

Em suma, para Voegelin (2007a, p. 117) “a razão e o espírito são os dois modos 
de constituição do homem, os quais foram generalizados com a ideia de homem". Isto é, o nous e o pneuma são lados diferentes da mesma moeda, e lançam luz no mesmo estado de coisas: a unidade do fundamento transcendente do cosmos, do mundo e do homem. $\mathrm{O}$ homem não pode ser explicado restringindo-se apenas à imanência. Ainda mais, o que é puramente imanente para essas tradições não é mais do que uma abstração que não encontra nenhum correlato real. Não só o mundo é parte de uma ordem que o supera, como a consciência é "tocada" pela mesma "luz" transcendente que irradia ordem no mundo, ou seja, pela luz da ordem cósmica. A dimensão imanente não é capaz de traduzir a experiência integral da realidade, porque é incapaz de explicar a ordem noética e pneumática. Portanto, fechar-se à transcendência é fechar-se à verdade sobre a experiência da realidade e sobre o homem.

Como o "fechamento" à esfera transcendental é o motivo constitutivo do "credo" que formará as ideologias gnósticas, que se encontram, por sua vez, na base do totalitarismo, a conclusão óbvia é que o totalitarismo é um perigoso fruto de uma interpretação limitada, parcial, acósmica.

Como já dito, Voegelin (2007a) aponta para o fato de que essas dimensões, noética e pneumática, revelam que há um elemento ordenador cósmico transcendente, e que o homem, a seu modo, enquanto livre, também participa dessa ordem. Ora, uma das consequências dessa revelação é o alcance de uma certa consciência de liberdade:

Por meio da experiência do Ser transcendente, simbolizada na revelação e na filosofia, os homens se libertam da velha ordem imperial, na forma cosmológica. A fonte divina do Ser está num para além transcendente, e nenhuma divindade terrena medeia sua eficácia (SANDOZ, 2010, p. 224).

O fundamento divino transcendente liberta o homem do domínio dos "deuses" imanentes, isto é, de imperadores, reis ou governantes que evocam para si (ou sua classe, grupo, partido, raça ou cultura) uma aura divina. Mesmo eles estão sujeitos à ordem divina e quando não regem seus domínios de acordo com essa ordem perdem sua legitimidade. A descoberta do fundamento transcendente do homem explicita uma também fundamental igualdade entre os homens. Estes não estarão, de fato, submetidos ao arbítrio voluntarioso de qualquer homem ou partido, classe, grupo, raça ou cultura que se julgue superior, porque são, em último caso, ordenados por uma lei ou normatividade que impera igualmente sobre todos, tornando-os, portanto, todos sujeitos a ela, de tal modo que, literalmente, ninguém estaria acima dessa lei transcendente. $\mathrm{O}$ fundamento do ser é compartilhado por todos como uma centelha de luz inteligível acessível em cada homem e para cada um deles. A partir dessa descoberta, o homem não precisa mais submeter-se ao deus-rei ou a aristocratas de "descendência mítica"; Sócrates não precisa se submeter à pressão da opinião da maioria; Moisés não precisa se submeter à autoridade do faraó. A descoberta da participação no fundamento divino da realidade concede liberdade ao homem e a consciência da grandeza e dignidade não só de si, mas de cada outro homem.

É justamente quando essa ordem divina (do cosmos, do mundo, do homem) é "esquecida" ou "sufocada", deteriorando-se as dimensões noética e pneumática, que a realidade se desfigura e, com ela, o homem:

Em ambos os casos, ocorre uma perda da realidade, já que esse ser divino, esse fundamento de ser, é, na verdade, a realidade também, e se alguém se fecha a essa realidade, esse alguém não possui a experiência dessa parte da realidade, essa parte decisiva que constitui o homem. (VOEGELIN, 2007a, p. 118-119).

Acontece, dessa maneira, a des-transcendentização do mundo e do homem, com 
o consequente abandono ao arbítrio das ideologias, que pretendem forçar a realidade a adequar-se à sua lógica. Entre essas estão as ideologias imanentistas que prometem realizar o sentido da história ou da natureza, como os movimentos totalitários. A abertura às dimensões do nous e do pneuma quando empobrecida, traz consequências no que diz respeito à ordenação da consciência e do comportamento do indivíduo. Aqui se caracteriza o que Voegelin chamará de doença do espírito. Seu principal sintoma é a “[...] estupidez no pensar e no agir" (VOEGELIN, 2007a, p. 132).

A estupidez no pensar e no agir não é simplesmente falta de "erudição", mas de senso comum, que não significa conhecimento irrefletido, mas hábito civilizacional, apoiado em uma experiência noética

[...] não conota um lastro de ideais vulgares [...], nem uma "visão de mundo relativamente natural". [...] O senso comum é um hábito civilizacional que pressupõe experiência noética, sem o homem deste hábito possuir ele mesmo conhecimento diferenciado da noese. O homo politicus civilizado não precisa ser filósofo, mas tem de ter senso comum (VOEGELIN, 2009a, p. 511).

Essa noção de senso comum identifica-se com a ideia de bom senso ou senso de humanidade. Sem ele, não há vida social e política: "há certo grau dele que é necessário para sermos sujeitos da lei e do governo, capazes de regermos nossos próprios negócios, e responsáveis pela nossa conduta para com os outros" (REID, 1969, p. 559, apud VOEGELIN, 2009a, p. 510-511). A doença do espírito é a ausência desse senso de humanidade (bom senso), falta de senso comum; é a incapacidade espiritual que Voegelin identifica como estupidez.

Para tentar elucidar a noção de "estupidez", Voegelin faz uso da definição que o escritor austríaco Robert Musil (1880-1942) atribui ao termo, na obra O Homem sem Qualidades. Nessa direção, ela está associada à incompetência ou incapacidade para desempenhar determinada tarefa ou decisão considerada normal. Portanto, a "[...] estupidez é sempre relacionada com a normalidade de um comportamento social determinado" (VOEGELIN, 2007a, p. 133). Para enfatizar a especificidade dessa "estupidez espiritual", baseando-se nos escritos de Musil, Voegelin (2007a) apresenta a distinção entre estupidez simples (ou honrada) e estupidez elevada. A estupidez simples seria uma mera falta de entendimento ou compreensão; já a estupidez elevada seria:

[...] um distúrbio no equilíbrio do espírito. O espírito agora se torna o adversário, não a mente. Não é um defeito da mente como nas pessoas simples, mas um defeito do espírito [...]. Schelling já empregou a expressão "pneumopatologia" para distúrbios espirituais desse tipo. Isso significa que o espírito está doente, não a alma no sentido da psicopatologia: então, a doença espiritual, a doença do espírito, condições pneumopatológicas opostas a condições psicopatológicas. (VOEGELIN, 2007a, p. 137).

Em outros termos, a estupidez elevada não é uma psicopatologia, uma doença da psiquê; é uma pneumopatologia, uma doença do espírito. Essa condição não é intelectual, não está relacionada à ausência de inteligência, ou mesmo de conhecimento. Famosos intelectuais apoiaram e ajudaram a atrair o povo para o Nacional Socialismo, a exemplo de Carl Schmitt e Martin Heidegger. ${ }^{11}$ Não se trata, menos ainda, de uma ausência congênita de consciência moral, como pode ocorrer em casos de psicopatologia, mas de seu arrefecimento incomum, ou seja, por ação humana. ${ }^{12} \mathrm{~A}$ condição pneumopatológica significa que o ser humano não é mais capaz de definir corretamente suas ações e decisões, ou seja, de agir de acordo com valores embasados em uma ordem que constitui o bom senso. Esse estado de degeneração espiritual provoca, portanto, um abalo do senso ético, uma perda da habilidade de refletir e 
decidir humanamente - ou seja, pautado em princípios e valores ligados ao bom senso -, sobre qual conduta é boa, correta e justa. O sujeito com essa pneumopatologia converte-se em um indivíduo que não possui mais a "consciência moral" para orientar ou refrear suas ações e desejos e, em tantos casos, conscientemente procura destruí-la em si e nos outros.

Os fatores que promovem a pneumopatologia são os mesmos que geram e alimentam o gnosticismo, condensados a partir do abandono abrupto de uma tradição e, consequentemente, de todo senso comum, ou bom senso, construído por uma experiência secular, alimentada, por sua vez, por erros e acertos, já que falhas, enganos e correções fazem parte de toda dinâmica civilizacional. Em outros termos, pretender a melhora das condições de existência é uma ambição de qualquer sociedade humana. Mas, há situações em que a mudança representa um ponto de inflexão, depois do qual algo se "quebra".

A Civilização Ocidental - fundamentada pela cultura greco-romana, por um lado, e judaico-cristã, por outro -, atinge no século XX um ponto de inflexão, quando a profunda descristianização do ocidente e uma das maiores crises já enfrentadas pela cultura e, especialmente, pela filosofia (ORTEGA Y GASSET, 2016), evidenciam sem sombras de dúvida a diminuição da influência da cultura tradicional. Indivíduos, cuja comunidade de origem antes se pautava em valores tradicionais, isolados pela dinâmica das sociedades industriais e pelo secularismo, imergiram em uma profunda "crise" moral e espiritual, uma pneumopatologia.

A princípio, isso parece ser algo inofensivo, já que um único homem ou poucos deles com essa doença do espírito não representam ameaça à civilização. Porém, quando essa pneumopatologia acomete um número significativo de pessoas, quando se torna um fenômeno de massas, a situação torna-se perigosa. Uma massa "moralmente inconsciente", liderada por alguém que também é portador dessa doença do espírito ou mesmo por psicopatas - é o ingrediente sine qua non para a consolidação dos regimes totalitários.

\section{CONSIDERAÇÕES FINAIS}

Voegelin pauta suas reflexões em uma filosofia da história que direciona sua análise para o estudo da influência que fatores espirituais (gnosticismo imanentista, experiência pneumática e noética) e sua deterioração tiveram na constituição dos movimentos totalitários. É evidente que as considerações de Voegelin a esse respeito são diferentes da maioria daquelas que outros filósofos e pesquisadores desenvolveram a respeito das causas que contribuíram para o surgimento dos movimentos totalitários. Comumente, os diagnósticos e exames apontam para influência que fatores como os ideais racialistas, a crise do sistema partidário, o surgimento das massas e a ação da propaganda ideológica tiveram na propagação e adesão às ideologias totalitárias. No entanto, vale ressaltar que a visão voegeliniana não anula esses diagnósticos. $\mathrm{Na}$ realidade, essas diferentes interpretações são conciliáveis e, até mesmo, complementares.

Os diversos fatores sociais e históricos, há pouco referidos, só tiveram eficácia enquanto instrumentos de manipulação ideológica porque encontraram uma imensa parcela da população que apresentava condições espirituais favoráveis, ou a falta delas, como apontado por Voegelin em seus escritos. Foi a doença espiritual que afligiu a consciência dos sujeitos, deixando-os à mercê da manipulação. Isso não quer dizer que a liberdade desses indivíduos foi anulada. Uma hipótese desse tipo não explicaria os 
resistentes. As investigações de Voegelin advogam a tese, encontrando muitos indícios para sustentá-la, de que os homens podem ser mais ou menos suscetíveis a boas e más influências. Em suma, a pneumopatologia não ocorre sem a adesão da vontade, mas a vontade é orientada por uma inteligência mais ou menos preparada para resistir de acordo com o que se julga ser de bom senso. Uma compreensão mais abrangente do totalitarismo exige levar em consideração, o quanto possível, os diversos fatores que nele confluem, sejam os instrumentos históricos, sociais, políticos e tecnológicos, que permitem o funcionamento dos mecanismos totalitários, sejam as condições mais radicais (fundamentais) que fazem com que o espírito humano se torne a eles suscetível. Neste sentido, perspectivas como a de Voegelin são também imprescindíveis.

Os movimentos e ideologias totalitárias, fenômenos típicos do século $\mathrm{XX}$, deixaram memórias amargas de acontecimentos que o senso comum cuidou em reprovar. Mas, é de bom senso aprender com essa experiência passada. Sem poder mudar o passado, é possível promover uma ação "profilática" para evitar que erros se repitam. A respeito dessa questão, na hipótese de Eric Voegelin está correto, há ainda hoje muitos motivos de preocupação. De fato, podemos afirmar que nossa civilização está livre da pneumopatologia? Chega a parecer evidente que não saímos dessa crise.

\section{REFERÊNCIAS}

ABBAGNANO, Nicola. Dicionário de Filosofia. Edição revisada e ampliada. Trad. Alfredo Bosi; Ivone Castilho Benedetti. São Paulo: Martins Fontes, 2007. 1014 p.

ADLER, Mortimer J.; DOREN, Charles Van. Como ler livros: o guia clássico para a leitura inteligente. São Paulo: É Realizações, 2010. 430 p.

ARISTÓTELES. Metafísica. Vol. II. São Paulo: Loyola, 2002. 577p.

FARÍAS, Victor. Heidegger e sua herança: o neonazismo, o neofascismo e o fundamentalismo islâmico. São Paulo: É Realizações, 2017. 262 p.

FAYE, Emmanuel. Heidegger: a introdução do nazismo na filosofia. São Paulo: É Realizações, 2015. $605 \mathrm{p}$.

FEDERECI, Michael P. Eric Voegelin: a restauração da ordem. Trad. Elpídio Mário Dantas Fonseca. São Paulo: É Realizações, 2011. 215 p.

FERGUSON, Sinclair B.; WRIGHT, David F. Novo Dicionário de Teologia. São Paulo: Hagnos, 2009. $1223 \mathrm{p}$.

LOBACZEWSKI, Andrew. Ponerologia: Psicopatas no poder. Campinas: Vide Editorial, 2014. $298 \mathrm{p}$.

ORTEGA Y GASSET, José. O que é filosofia? Campinas: Vide Editorial, 2016. 291p.

PLATÃO. Teeteto. 3. ed. Lisboa: Fundação Calouste Gulbenkian, 2010. 322p.

RUSSELL, Bertrand. History of Westerns Philosophy. Traduzione italiana di Luca Pavolini: Storia della Filosofia Occidentale. Milano: TEA, 1991. 816p.

SANDOZ, Ellis. A Revolução Voegeliniana: uma introdução biográfica. Trad. Elpídio Mário Dantas Fonseca. São Paulo: É Realizações, 2010. 398 p.

VOEGELIN, Eric. A Nova Ciência da Política. $2^{\mathrm{a}}$ ed. Trad. José Viegas Filho. Brasília: Editora Universidade de Brasília, 1982. 187 p.

VOEGELIN, Eric. Anamnese. Da teoria da história e da política. Trad. Elpídio Mário Dantas Fonseca. São Paulo: É Realizações, 2009a. 543 p.

VOEGELIN, Eric. As Religiões Politicas. Trad. Teresa Marques da Silva. Lisboa: Vega Limitada, 2002. $97 \mathrm{p}$.

VOEGELIN, Eric. Ciencia, Política y Gnosis. In: . El asesinato de Dios y otros escritos políticos. Buenos Aires: Hydra, 2009b. p. 69-123.

VOEGELIN, Eric. Hitler e os Alemães. Trad. Elpídio Mário Dantas Fonseca. São Paulo: É Realizações, 2007a. 367 p.

VOEGELIN, Eric. Reflexões Autobiográficas. Trad. Maria Inês de Carvalho. São Paulo: É 
Realizações, 2007b. 190 p.

WEBB, Eugene. Eric Voegelin: philosopher of history. Washington: University Of Washington Press, 2014 (Kindle).

\section{Notas}

* O presente artigo é parte de uma pesquisa desenvolvida junto ao programa de Mestrado Profissional em Filosofia - PROF-FILO, ofertado pela Universidade do Estado do Rio Grande do Norte - UERN/Campus Caicó. O texto foi apresentado no "IV Colóquio Internacional Estética e Existência: Filosofia e Espiritualidade", promovido entre 20 e 22 de novembro de 2019, na Universidade Federal da Paraíba/UFPB, em João Pessoa$\mathrm{PB} /$ Brasil.

1 Em uma breve definição, o termo Gnosticismo é comumente empregado para designar correntes filosóficas e religiosas que se desenvolveram, tanto no Ocidente quanto no Oriente, nos primeiros séculos depois de Cristo. Essas correntes são constituídas pela "mistura de elementos cristãos, míticos, neoplatônicos e orientais. [...] Em geral, para os gnósticos o conhecimento era condição para a salvação" (ABBAGNANO, 2007, p. 485). Dessa forma, fica claro que a característica essencial desses movimentos é a ideia de que a gnósis (termo grego que significa "conhecimento") é a chave para a salvação.

2 Este escrito está presente no livro intitulado El asesinato de Dios y otros escritos políticos. Como a versão utilizada no presente artigo está escrita em espanhol, os trechos citados em língua portuguesa (traduzidos pelos autores deste artigo) serão acompanhados por notas de rodapé que apresentam as suas versões em língua espanhola.

3 "La caida de los imperios antiguos en Oriente, la pérdida de la independencia de Israel y de las ciudades-Estado helenicas y fenicias, los desplazamientos de poblacion, las deportaciones y esclavizaciones, y la interpenetracion de las culturas colocan a los hombres, sobre cuyas cabezas la historia se decide, en un extremo estado de extravio en la agitacion del mundo, de desorientacion espiritual, de inseguridad material y animica. La pérdida de sentido de la existencia por el derrumbe de las instituciones, de las culturas y de los lazos politicos suscito como respuesta el intento de comprender en una forma nueva el sentido de la vida humana, de reencontrar el sentido de la existencia en las condiciones de ese mundo. A estos intentos pertenecen, con un amplio rango de variaciones en lo que se refiere a la profundidad de la comprension y al contenido de verdad: la reinterpretacion estoica del hombre (para el cualla polis habia perdido el sentido) como polites [ciudadano] del kosmos, [...] las religiones de misterios, los cultos heliopolíticos de esclavos, la apocallptica judia, el cristianismo y el maniqueismo. En esta serie figura, como una de las mas magnfficas entre las nuevas creaciones de sentido, la gnosis" (VOEGELIN, 2009b, p. 75-76).

4 “[...] ya no es aquel bien ordenado, el kósmos en el que el hombre helenico se sentia en casa; tampoco es el mundo judeo-cristiano que Dios creó y halló bueno" (VOEGELIN, 2009b, p. 76-77).

5 Joaquim de Fiore (c. 1135-1202) desenvolveu uma interpretação elaborada e muito influente da história e do futuro, que expressou em escritos exegéticos e figuras simbólicas. Entendia o desenvolvimento histórico em termos de atividade da Trindade na história, de forma que essa última refletiria os relacionamentos trinitários. Como o Espírito procede do Pai e do Filho, assim uma era do Espírito se desenvolveria a partir da era do Antigo Testamento, do Pai, na era do Novo Testamento, do Filho. Entre diversos modos de pensar essa terceira era do Espírito, Joaquim a identificou com o milênio do Apocalipse. [...] O pensamento de Joaquim causou uma revolução na escatologia medieval: ele tornou possível, pela primeira vez no cristianismo dessa época, especular um progresso de forma teologicamente significativa no futuro da história do mundo (FERGUSON; WRIGHT, 2009, p. 570).

6 É o que, curiosamente, também afirma Bertrand Russel em sua História da Filosofia Ocidental: "O modo humano de confrontar-se com o ambiente externo não humano foi 
profundamente diferente nas diversas épocas. Os gregos, com o seu horror à impiedade e com a sua fé em uma Necessidade ou Fato superior mesmo a Júpiter, evitavam com cuidado tudo o que pudesse a eles parecer um abuso no confronto do universo. $\mathrm{O}$ medievo levou a submissão muito além: a humildade no confronto de Deus era o primeiro dever de um cristão. A iniciativa foi enfraquecida por este comportamento, e uma grande originalidade era dificilmente possível. O renascimento restaurou o orgulho humano, mas o empurrou até o ponto onde este dava origem à anarquia e ao caos. A sua obra foi em grande parte destruída pela Reforma e pela Contrarreforma. Mas a técnica moderna, mesmo não sendo de fato favorável à individualidade aristocrática do Renascimento, fez renascer o sentido da potência coletiva da comunidade humana. O homem, antes muito humilde, começa a pensar a si mesmo quase como a um Deus. [...] Em tudo isto vejo um grave perigo, o perigo daquela que poderia ser chamada a impiedade cósmica. O conceito de "verdade", como algo que depende de fatos completamente fora do controle humano, foi um dos modos com os quais a filosofia nos inculcou até agora o necessário elemento de humildade. Quando se afasta este obstáculo sobre a estrada do orgulho, faz-se um ulterior passo sobre a estrada que leva a certo tipo de loucura" (RUSSELL, 1991, p. 787778).

7 O psicólogo polonês Andrew Lobaczewski apresenta um estudo da influência da psicopatologia no nascimento e alimentação dos regimes totalitários em sua obra Ponerologia: psicopatas no poder (LOBACZEWSKI, 2014).

8 Como sustenta a hipótese lançada por uma série de artigos intitulados $A$ anatomia de um Ditador, publicados pelo historiador alemão Percy Ernst Schramm, na revista Der Spiegel. São esses artigos que levam Voegelin a lecionar as preleções que constituirão o seu Hitler e os Alemães, como um esforço para evitar que a juventude universitária alemã do pósguerra seja enganada por esse tipo de relato.

9 Como já esclarecido anteriormente, as versões dos textos em língua estrangeira trazidas para esse artigo são traduzidos pelos autores, que também deixam em notas de rodapé o texto originalmente consultado.

10 " [...] the presence of the transcendental pole of the tension of existence as a force ordering the soul from within" (WEBB, 2014, 1. 5006). Note-se que o texto não segue a orientação kantiana que distingue transcendente e transcendental. Nós, autores do artigo, então, resolvemos conservar a tradução mais aproximada do termo ao original.

11 A esse respeito, pode-se ler obras como Heidegger: a introdução do nazismo na filosofia, de Emmanuel Faye, ou Heidegger e sua herança: o neonazismo, o neofascismo e o fundamentalismo islâmico, de Victor Farías.

12 Os psicopatas, em todo caso, podem se beneficiar da pneumopatologia, procurando utilizá-la como meio de coação de seus colaboradores, como um vírus oportunista que prospera no enfraquecimento de suas vítimas. É o que propõe o psicólogo polonês Andrew Lobaczewski (2014) em sua obra Ponerologia: psicopatas no poder. 